\title{
Gabapentin as an antiepileptic drug in man
}

\author{
P CRAWFORD, E GHADIALI, R LANE, L BLUMHARDT, D CHADWICK \\ From the Department of Neurology, Walton Hospital, Liverpool, UK
}

SUMMARY Gabapentin, 1-(aminomethyl) cyclohexane acetic acid, is a GABA analogue whose antiepileptic properties were tested in a double blind cross-over trial design as add-on therapy in a dose ranging study which compared $300 \mathrm{mg}, 600 \mathrm{mg}$, and $900 \mathrm{mg} /$ day (each dose given for 2 months) in 25 patients with severe partial and generalised epilepsies. A dose related antiepileptic effect was observed. All three doses were well tolerated and no psychometric impairment was noted. No significant drug interactions were seen. The drug appears worthy of further assessment.

Gabapentin, 1-(aminomethyl) cyclohexane acetic acid (fig 1), is a GABA analogue that is well absorbed and penetrates the blood brain barrier. It is effective against a variety of seizures in animals particularly those caused by interference with GABAergic transmission or provoked by excitatory amino acids. ${ }^{1}$ In spite of this the precise mechanism of its antiepileptic properties is unclear as gabapentin does not appear to alter whole brain levels of GABA or have significant effects on GABA transaminase activity. It does not show any significant binding to GABA or benzodiazepine receptors and does not influence neuronal uptake of GABA at pharmacologically relevant doses. $^{1}$

We report the first study of the antiepileptic properties of gabapentin in 25 patients with severe epilepsies resistant to standard antiepileptic drugs. The effects of three different doses of the drug have been compared in a double blind crossover trial design.

\begin{abstract}
Methods
The trial design was that of a three way double blind crossover study. All patients were followed for an initial two month baseline period during which they received one or two standard antiepileptic drugs. Seizure frequency and adverse effects were documented. All patients then received a two week titration phase in which $300 \mathrm{mg}$ and $600 \mathrm{mg}$ of gabapentin was given. At the end of this time patients were randomised to receive $300 \mathrm{mg}, 600 \mathrm{mg}$, or $900 \mathrm{mg} /$ day of gabapentin. Their pre-existing therapy was maintained throughout the study. Each patient received each dose of the drug for 2 months. Patients were seen at monthly intervals
\end{abstract}

Address for reprint requests: Dr D Chadwick, Department of Neurology, Walton Hospital, Rice Lane, Liverpool L9 1AE, UK.

Received 3 June 1986 and in final revised form 18 August 1986. Accepted 30 August 1986 when seizure frequency and side effects were documented. Serum antiepileptic drug concentrations were recorded at each visit as well as levels of gabapentin.

Phenytoin, carbamazepine, primidone and phenobarbitone concentrations were measured by the method of Perchalski et al $^{2}{ }^{2}$ valproate levels by the method of Chard. ${ }^{3}$ Plasma gabapentin concentrations were estimated by an HPLC method. ${ }^{4}$ Routine haematological, serum biochemistry and urine analyses were performed at each visit.

Psychometric assessment was undertaken once during the baseline period and repeated during the second month of each treatment phase. A battery of tests known to be sensi- $\Omega$ tive to drug effects was chosen. These included choices reaction time, critical flicker-fusion threshold, spatial orientation, digit symbol latency, perceptual analysis, verbal andô visual memory. ${ }^{5-7} \mathrm{~A}$ computerised testing procedure was used for all tests except choice reaction time and critical flicker fusion.

\section{Patients}

Patients with partial or generalised epilepsies were admitted to the study as long as they had a definite history of epilepsy confirmed by observation and EEG recording, and suffered a minimum of one seizure per week. No patients were known to have progressive neurological disturbance.

Twenty five patients were recruited to the study. Fifteen were male and ten female. Age was between 18 and 53 years (mean $33 \pm 10$ years). The duration of epilepsy was between 6 and 40 years (median 18.5 years).

Eighteen patients had partial epilepsies. Thirteen had only partial seizures (simple partial seizures in two, complex partial seizures in 11), whilst five patients had both partial seizures and presumed secondarily generalised tonic-clonic seizures.

Seven patients had generalised epilepsies. This was primary in four patients: three had simple absences which occurred alone in one patient, in combination with brief tonic seizures in another, and in combination with tonic-clonic seizures in the third. One patient had tonic-clonic seizures alone. Three had a symptomatic generalised epilepsy: two patients had tonic seizures associated with tonic-clonic sei- 

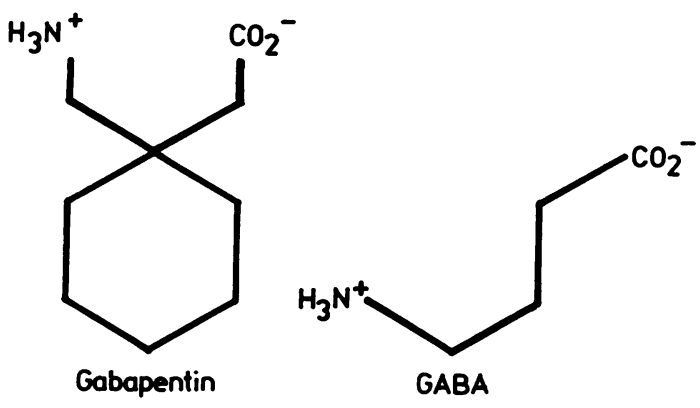

Fig 1 Structure of $G A B A$ and gabapentin.

zures, one patient had complex absences associated with tonic-clonic seizures.

Probable aetiological factors were identified in 15 patients. Perinatal insults had occurred in six patients, the epilepsy was post-encephalitic in three and post traumatic in two. One patient developed epilepsy after a prolonged febrile convulsion, and three patients had non-progressive structural lesions on CT scanning (two low density, one calcification). Neurological signs were present in two patients, one of whom was blind because of choroido-retinitis and one of whom had a mild left hemiparesis. Seven patients had an IQ of 80 or less.

Three patients were taking one standard antiepileptic drug and 22 were receiving two drugs (in three of these benzodiazepines were also prescribed). Carbamazepine was administered to 21 patients, valproate to 13 , phenytoin to 11 , primidone to one, and phenobarbitone to one. Doses of these drugs were such as to maintain adequate serum concentrations.

\section{Results}

\section{Efficacy}

Four patients were excluded from the analysis of efficacy. One patient developed absence status during the two week titration phase. Similar episodes occurred frequently in this patient and had occurred when he had previously been challenged with new anticonvulsant drugs. He did not enter the formal part of the study. Two patients were excluded from analysis because of questionable compliance and poor documentation of their seizures during the course of the study. One patient had phenobarbitone added to his therapy by the general practitioner during the course of the study.

All subsequent data on efficacy were derived from 21 patients. Three patients terminated the third treatment phase prematurely four weeks before it was due to end. All three patients showed evidence of reduced efficacy in the third period compared to previous periods. Two of these patients were receiving $300 \mathrm{mg} /$ day gabapentin in the third period and the third patient $900 \mathrm{mg} /$ day. Data from these patients has been in-
Table 1 Seizure frequency (Seizure/week)

\begin{tabular}{|c|c|c|c|c|}
\hline & Baseline & $300 \mathrm{mg}$ & $600 \mathrm{mg}$ & $900 \mathrm{mg}$ \\
\hline \multicolumn{5}{|c|}{ All seizures $(\mathrm{N}=21)$} \\
\hline Median & $3 \cdot 3$ & $2 \cdot 5$ & 3.0 & \\
\hline $25 \%$ quartile & 1.4 & & $1 \cdot 1$ & \\
\hline $75 \%$ quartile & $11 \cdot 4$ & $8 \cdot 3$ & $7 \cdot 3$ & $5 \cdot 2$ \\
\hline $\begin{array}{l}\text { Range } \\
\text { Partial seizures } \theta\end{array}$ & $0.9-102$ & $0 \cdot 6-90$ & $0-99$ & $0 \cdot 3-89$ \\
\hline \multicolumn{5}{|c|}{ Partial seizures $(N=14)$} \\
\hline Median & 2.5 & $2 \cdot 4$ & $1 \cdot 3$ & $1 \cdot 2$ \\
\hline $25 \%$ quartile & 0.8 & 1.0 & 0.6 & 0.5 \\
\hline $75 \%$ quartile & $9 \cdot 7$ & $13 \cdot 7$ & $10 \cdot 1$ & $4 \cdot 8$ \\
\hline Range & $0 \cdot 3-102$ & $0-90$ & $0-99$ & $0-89$ \\
\hline \multicolumn{5}{|c|}{ Tonic-clonic seizures $(\mathbf{N}=11)$} \\
\hline Median & 1.0 & 0.8 & 0.5 & $0 \cdot 3$ \\
\hline $25 \%$ quartile & 0.4 & 0.4 & 0.3 & $0 \cdot 1$ \\
\hline $75 \%$ quartile & 2.9 & 1.9 & $2 \cdot 1$ & 1.6 \\
\hline Range & $0 \cdot 3-5 \cdot 3$ & $0 \cdot 1-5$ & $0 \cdot 3-4 \cdot 6$ & $0-6 \cdot 1$ \\
\hline
\end{tabular}

cluded in the analysis using frequencies calculated as seizures per week.

Seizure frequency in the four periods of observation is presented in table 1 and for individual patients the percentage change in seizure frequency from baseline is presented for each dose in fig 2 and table 2 (for all seizure types combined, for patients with partial seizures and for tonic-clonic seizures whether these occurred on a primary or secondarily generalised basis). Too few patients in the study were suffering from absence seizures or other primary generalised seizures to warrant separate analysis.

All statistical comparisons were within patient tests. The Wilcoxson signed rank test was used to compare seizure frequencies between baseline and individual doses $(30 \mathrm{mg}, 600 \mathrm{mg}, 900 \mathrm{mg} /$ day $)$. Comparisons of the relative efficacy of different gabapentin doses was undertaken using the Friedman test with subsequent multiple comparisons by the Wilcoxson-Wilcox method.

The median frequency of all seizures was reduced from 3.3 to $2 \cdot 1$ /week $(45 \%)$ on $900 \mathrm{mg}$ /day of gabapentin compared to baseline period $(p<0.001)$. The $300 \mathrm{mg}$ and $600 \mathrm{mg}$ doses did not differ significantly from baseline. The three doses differed significantly (Friedmann test $\mathrm{p}<0.001$ ). The $900 \mathrm{mg}$ dose was significantly better than $600 \mathrm{mg}(\mathrm{p}=0.05)$ and $300 \mathrm{mg}(\mathrm{p}=0.01)$. Nine patients $(43 \%)$ had seizure frequency reduced by at least $50 \%$ whilst receiving $900 \mathrm{mg} /$ day gabapentin, whilst seven and three patients respectively experienced $50 \%$ reduction in seizure frequency whilst receiving $600 \mathrm{mg}$ and $300 \mathrm{mg}$ gabapentin. A single patient was entirely free of seizures for the full 2 month treatment period whilst receiving $600 \mathrm{mg}$ per day.

Similar trends towards improvement with increasing doses of gabapentin were seen for both partial seizures and tonic-clonic seizures. The most striking effect of gabapentin appeared to be in the reduction of tonic-clonic seizures. 


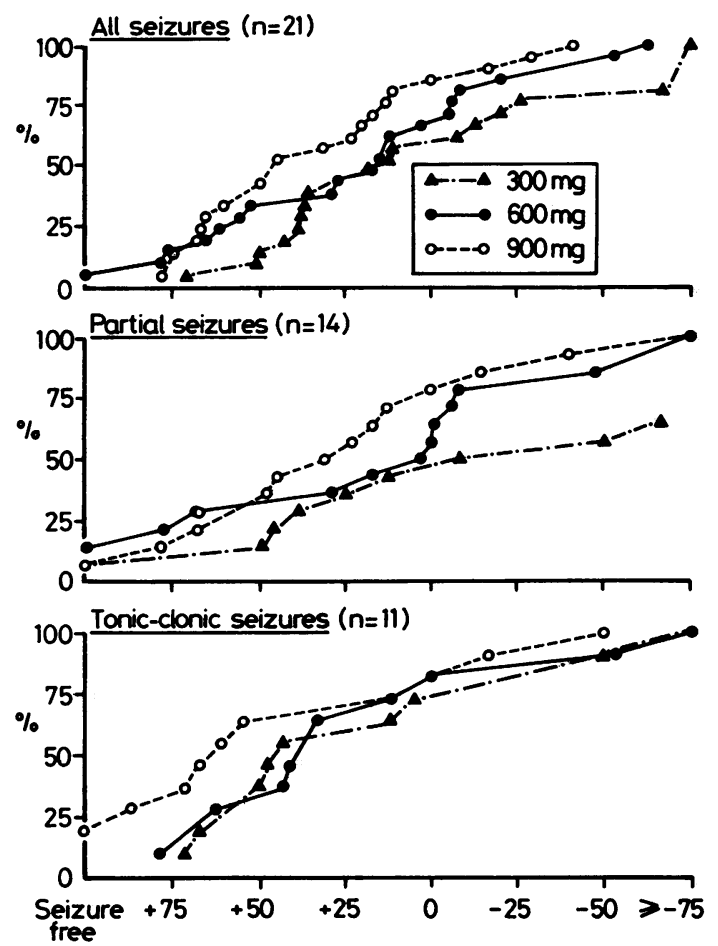

Fig 2 Cumulative distribution of patients as their percentage change in seizure frequency from baseline at doses of $300 \mathrm{mg}, 600 \mathrm{mg}$ and $900 \mathrm{mg}$ gabapentin, for all seizures, partial seizures and tonic-clonic seizures. Vertical axis is \% of $N$ patients showing appropriate change in seizure frequency or better. Horizontal axis is change in seizure frequency relative to baseline period ( $O=$ no change, positive values $=\%$ improvement, negative values $=\%$ deterioration. Differences as follows:

Wilcoxon-Wilcox

\begin{tabular}{llll}
\cline { 3 - 4 } & Friedman & 900 vs 300 & 900 vs 600 \\
\hline All seizures & $p<0.001$ & $p=0.01$ & $p=0.05$ \\
Partial & $p=0.034$ & $p=0.05$ & $p=n . s$. \\
Tonic-clonic & $p=0.044$ & $p=$ n.s. & $p=$ n.s.
\end{tabular}

Fifteen patients and the supervising clinician were sufficiently impressed by the efficacy of the drug to continue prescription of gabapentin in an open fashion following the formal completion of the study.

\section{Adverse effects}

Data from all 25 patients have been included. One patient developed absence status as previously described. Other adverse effects are summarised in table 3. Eight patients reported one or more adverse effects whilst taking $300 \mathrm{mg}, 15$ patients reported adverse effects on one or more occasion taking $600 \mathrm{mg} / \mathrm{day}$ and 11 patients reported adverse effects whilst taking
Crawford, Ghadiali, Lane, Blumhardt, Chadwick

Table 2 Efficacy: change in seizure frequency for each dose compared with baseline

\begin{tabular}{|c|c|c|c|c|c|}
\hline & \multicolumn{5}{|c|}{ Nos of patients } \\
\hline & $>75 \%$ & $\begin{array}{l}\text { Improved } \\
74-50 \%\end{array}$ & $49-0 \%$ & Worse & Total \\
\hline \multicolumn{5}{|l|}{ All seizures } & \multirow[t]{4}{*}{21} \\
\hline $300 \mathrm{mg} /$ day & 0 & 3 & 9 & 9 & \\
\hline $600 \mathrm{mg} / \mathrm{day}$ & 3 & 4 & 7 & 7 & \\
\hline $900 \mathrm{mg} /$ day & 3 & 6 & 9 & 3 & \\
\hline \multicolumn{5}{|l|}{ Partial seizures } & \multirow[t]{4}{*}{14} \\
\hline $300 \mathrm{mg} /$ day & 1 & 1 & 4 & 8 & \\
\hline $600 \mathrm{mg} /$ day & 3 & 1 & 4 & 6 & \\
\hline $900 \mathrm{mg} /$ day & 2 & 2 & 7 & 3 & \\
\hline \multicolumn{6}{|l|}{ Tonic-clonic } \\
\hline seizures & & & & & \multirow[t]{4}{*}{11} \\
\hline $300 \mathrm{mg} /$ day & 0 & 4 & 4 & 3 & \\
\hline $600 \mathrm{mg} /$ day & 1 & 2 & 6 & 2 & \\
\hline $900 \mathrm{mg} /$ day & 3 & 4 & 2 & 2 & \\
\hline
\end{tabular}

$900 \mathrm{mg}$ of gabapentin. Six patients reported some adverse effects of their therapy at admission to the study. In no case were the side effects sufficient to warrant premature termination of the study.

Screening of haematological and biochemical parameters was undertaken prior to the commencement of therapy and at monthly intervals whilst on active treatment. Whilst a number of patients had estima tions of these parameters which fell slightly outsideo the normal ranges, such deviations were no more fre- $-\AA$ quent whilst receiving gabapentin than prior to the study.

Psychometric testing failed to reveal any changeso between baseline and active treatment or between $-\overrightarrow{0}$ different doses of gabapentin, indicating no impairment of performance on the tests used.

Compliance and antiepileptic drug concentrations Blood was collected for estimation of the serum concentrations of the standard antiepileptic drugs and gabapentin during the course of a morning clinic. Thus serum concentrations relate to levels between 10

Table 3 Adverse effects

\begin{tabular}{lll}
\hline Symptom & $\begin{array}{l}\text { Antiepileptic drugs } \\
\text { (Baseline) }\end{array}$ & $\begin{array}{l}\text { Gabapentin }+ \\
\text { antiepileptic drugs }\end{array}$ \\
\hline $\begin{array}{l}\text { Nervous System: } \\
\text { Absence status }\end{array}$ & 8 & 1 \\
$\begin{array}{l}\text { Drowsiness } \\
\text { Tiredness }\end{array}$ & 11 \\
$\begin{array}{l}\text { Dizziness } \\
\text { Slurred speech }\end{array}$ & 7 \\
$\quad$ Less alert & 2 \\
$\quad \begin{array}{l}\text { Tremor } \\
\text { Other poorly specified } \\
\quad \text { complaints }\end{array}$ & 1 & 1 \\
$\begin{array}{l}\text { Skin and Appendages } \\
\text { (rash) }\end{array}$ & 1 & 1 \\
$\begin{array}{l}\text { Gastrointestinal } \\
\text { (nausea) }\end{array}$ & 2 & 7 \\
\hline
\end{tabular}


Table 4 Standard antiepileptic drug serum concentrations

\begin{tabular}{|c|c|c|c|c|}
\hline \multirow[b]{3}{*}{$\begin{array}{l}\text { Phenytoin } \\
\text { Valproate } \\
\text { Carbamazepine } \\
\text { Phenobarbitone }\end{array}$} & \multirow[b]{2}{*}{ Baseline } & \multicolumn{3}{|c|}{ Gabapentin dose (mg/day) } \\
\hline & & \multicolumn{3}{|c|}{ (mean $\pm S D) \mu g / m l$ (number of patients) } \\
\hline & $\begin{array}{r}9.7 \pm 3.9 \text { (9) } \\
89.6 \pm 41.7(12) \\
8.1 \pm 2.4(17) \\
13.0\end{array}$ & $\begin{array}{r}9 \cdot 4 \pm 3 \cdot 7(9) \\
60.8 \pm \pm 0.4(12) \\
7.6 \pm 2 \cdot 2(18) \\
13.0\end{array}$ & $\begin{array}{r}9.9 \pm 5.4(7) \\
64.8 \pm 34.4(10) \\
8.1 \pm 2.4(15) \\
6.5\end{array}$ & $\begin{array}{r}12.1 \pm 5.8 \text { (8) } \\
84.9 \pm 46.5(9) \\
8.3 \pm 2.3(14) \\
12.0\end{array}$ \\
\hline
\end{tabular}

and $11 \mathrm{am}$, two to three hours after the initial dose of anticonvulsants.

Serum concentrations of standard antiepileptic drugs are presented in table 4 during baseline and during the three treatment periods. There was no change in any baseline blood levels although there was a trend towards elevation of serum phenytoin
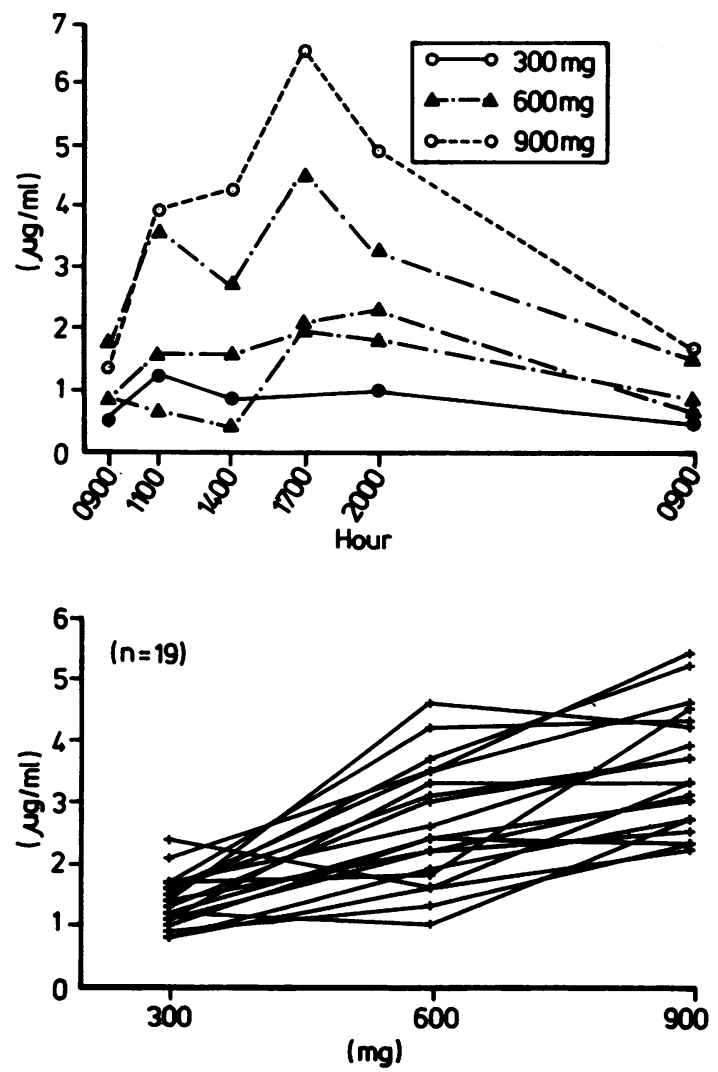

Fig 3 (a) Plasma gabapentin concentrations over 24 hours in five patients receiving thrice daily dosing $(09.00,14.00$, 20.00 ) with gabapentin $300 \mathrm{mg} /$ day (1 patient), $600 \mathrm{mg} /$ day (3 patients) and $900 \mathrm{mg} /$ day (1 patient). (b) Mean plasma concentrations of gabapentin for 19 patients receiving all three doses of gabapentin. Sampling at approximately 11.00 am and following 09.00 am dosage. concentration in patients taking $900 \mathrm{mg} /$ day of gabapentin.

Detailed plasma concentration assays for gabapentin were undertaken in five patients during 24 hour periods when they were receiving $900 \mathrm{mg}$ per day (one patient), $600 \mathrm{mg}$ per day (three patients), and $300 \mathrm{mg}$ per day (one patient) (fig 3a). It can be seen that blood levels at $11 \mathrm{am}$., two hours after the initial dose of gabapentin, are approximately twice the trough levels, but the peak levels during the 24 hours were attained at approximately $1700 \mathrm{hrs}$ (three hours after the midday dose). Similar 24 hour monitoring in each of these five patients was repeated two weeks later. Repeat testing did not show any evidence of auto-induction.

Mean concentrations of gabapentin for each patient at the three doses of gabapentin that they received are presented in fig $3 \mathrm{~b}$. It can be seen that there is a satisfactory linear relationship between dose and serum concentration in all cases where serum sampling time was similar (19 patients).

\section{Discussion}

Over recent years there has been an increased understanding of the role of the inhibitory neurotransmitter, GABA, in the control of seizure threshold. This has achieved direct clinical relevance with clinical testing of $\gamma$-vinyl GABA, a GABA transaminase inhibitor, ${ }^{8}$ and progabide, a GABA prodrug and GABA agonist, ${ }^{9}$ as potential antiepileptic drugs. Gabapentin was synthesised as a GABA analogue and whilst it appears to possess GABA mimetic properties its precise mode of action remains uncertain.

This first study was designed to compare the relative efficacy of three different doses of gabapentin in patients with severe partial and generalised epilepsies. The results indicate that $900 \mathrm{mg} /$ day of gabapentin has greater antiepileptic properties than $300 \mathrm{mg}$ and $600 \mathrm{mg} /$ day against all seizure types considered together. There is evidence of a dose related antiepileptic effect that is statistically significant when all seizures are considered together and similar trends are seen when partial seizures, and tonic-clonic seizures are considered separately. The median frequency of tonic-clonic seizures was reduced most dramatically. 
Whilst the direct dose to dose comparisons infer antiepileptic efficacy they cannot be regarded as providing definite proof. Whilst the median frequency of all seizures was reduced by $30 \%$ compared with baseline frequency $(50 \%$ reduction for partial seizures, and $70 \%$ reduction for tonic-clonic seizures) these results must be interpreted with caution. There was no random allocation between baseline period and a drug dosage, and placebo was not given during the baseline period. Whilst it seems highly unlikely that the results can be explained by a placebo effect, this present trial design cannot definitely exclude such a possibility.

The study relates only to a relatively short period of treatment. However, some 15 patients have continued gabapentin therapy for periods now approaching 12 months. So far there is no evidence of the development of tolerance in the antiepileptic effects of gabapentin in our patients.

It is of some interest to compare the results of this study with those of another study recently performed in this department. This was also a three-way crossover study comparing the addition of progabide, valproate and placebo as add-on therapies. ${ }^{9}$ Whilst the trial designs differ in that in the latter study treatment periods were for 6 months, and there was random allocation between placebo and the two active drugs, the majority of patients taking part in the gabapentin study also took part in the previous study. We cannot draw firm conclusions but the results obtained with gabapentin appear quantitatively very similar to those obtained with valproate and the spectrum of activity of valproate and gabapentin appear similar, both being moderately effective against partial seizures and highly effective against tonic-clonic seizures.

This study has shown little evidence of adverse effects and detailed psychometric testing failed to show any significant changes. Importantly, there was no evidence that gabapentin has significant interactions with other antipileptic drugs. This may have been expected as the drug is largely excreted unmetabolised, and does not undergo significant protein binding.

Gabapentin thus appears to be a promising anti- epileptic drug. The next necessary step will be a direct proof-of-efficacy study comparing gabapentin with placebo in a double-blind fashion as add on therapy. If further study confirms the present impressions of an effective antiepileptic drug relatively free of side effects and drug interaction, there is every possibility that gabapentin may prove a significant addition to the range of drugs available for the treatment of human epilepsy.

We are grateful to Godecke for financial support and statistical analysis of the data, and to our colleagues for allowing us to study their patients.

\section{References}

1 Bartoszyk GD, Meyerson N, Reimann W, Satzinger G, Von Hodenberg A. Gabapentin: preclinical profile and first clinical results. In: Meldrum BS, Porter RJ, eds. Current problems in Epilepsy. IV-New Anticonvulsant Drugs. London 1986: John Libbey 147-64.

2 Perchalski RJ, Scott KN, Wilder RJ, Hammer RH. Rapid simultaneous GLC determination of phenobarbital, primidone and diphenylhydantoin. J Pharm Sci 1973;62:1735-6.

3 Chard CR. A simple method for the determination of Epilim in serum. In: Legg $\mathrm{N}$, ed. Clinical \& Pharmacological Aspects of Sodium Valproate (Epilim) in the Treatment of Epilepsy. Tunbridge Wells: M.C.S., 1976:89-91.

4 Hengy H, Kolle E-U. Determination of gabapentin in plasma and urine by high performance liquid chromatography and pre-column labelling for ultraviolet detection. J Chromatogr 1985;341:473-8.

5 Hindmarch J. Psychomotor function and psychoactive drugs. Br J Clin Pharmacol 1980;10:145-51.

6 Smith JM, Misiati H. Critical flicker frequency and psychotropic drugs in normal subjects: a review. Psychopharmacology 1976;47:175-86.

7 Acker W, Actier C. Bexley Maudsley automated psychological screening test. Windsor: NFER, Nelson Publishing 1982.

8 Rimmer EM, Richens A. Double-blind study of $\gamma$-vinyl GABA in patients with refractory epilepsy. Lancet 1984;1:189-90.

9 Crawford P, Chadwick D. A comparative study of progabide, valproate and placebo as add-on therapy in patients with refractory epilepsy. $J$ Neurol Neurosurg Psychiatry 1986;49:1251-7. 